\title{
LA CRISIS DE LA ESTETICA MUSICAL en el Doctor Faustus de Thomas ManN
}

\author{
Gustavo Adolfo Henao \\ Estudiante de Filosofia y Letras de la Universidad de Caldas. \\ Patricia Noguera \\ Profesora Asociada, Universidades Nacional \\ y Autónoma de Manizales.
}

Se ha tendido a definir al novelista alemán Thomas Mann como el último gran representante de la literatura burguesa europea, aunque esta opinión encierra el peligro de fáciles y simples interpretaciones. Mann, quien a sus 25 años ya habia configurado en los Buddenbrook sus lineamientos temáticos y estilísticos que desarrollaría en adelante, se nos aparece desde entonces como un artista que no disfruta de la marginalidad, del desarraigo frente a la herencia prusiana de la ética del trabajo y la disciplina de progreso; se sabe artista pero se siente, al igual que su personaje Tonio Kröger, como un ser escindido, entre otros aspectos, de aquellas actividades que su familia en Lübeck ejercitaba con todo su empeño, pero frente a las cuales su espiritu se resistía a asumir con espontaneidad y, menos aún como imperativo moral.

El hecho cultural del romanticismo alemán, y en general de occidente, fué sólo un impulso fallido-sóloen cuanto concepción de la utopiade un proyecto histórico fracasado: la Ilustración burguesa. Si bien el romanticismo se mostró como la más auténtica respuesta expresiva del hombre del siglo XIX desde el

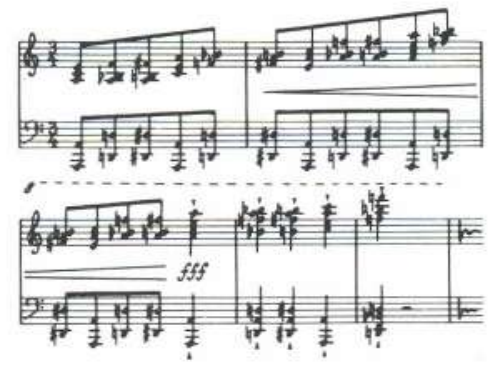

punto de vista de la estética. Thomas Mann se encuentra interiormente sitiado por fuerzas que se resisten a sucumbir y además por el desencadenamiento de fuerzas reactivas nacidas de ese mismo proceso. En otras palabras, Mann siente que aún es menester administrar el legado de la gran tradición alemana que es clásica en su forma y optimista en la autoeducación del yo y en la posibilidad de canalizar armónicamente todos los impulsos humanos, no hacia una expresión descarnada de la sensibilidad humana o hacia una 'ebriedad emotiva' sino hacia una corriente teórica que es representada específicamente por la prosa de formación de un Göethe y posteriormente de Lessing. A ese humanismo conciente de las complejidades y la belleza trágica de la interioridad humana se yuxtapone complementariamente la visión Manniana de la vida. Ya Wagner habria de influirlo en su preocupación por el concepto de la 'obra de arte' monumentaly de alguna manera a ponerlo en guardia frente al mismo Wagner en cuanto a las peligrosas tendencias románticas a la evasión reaccionaria a lo primitivo; pero de otro lado fué marcado también por el lúcido juicio histórico de Nietzsche: el anuncio del nihilismo, el diagnóstico latente de la crisis de aquel humanismo y de cierta sensibilidad romántica. 


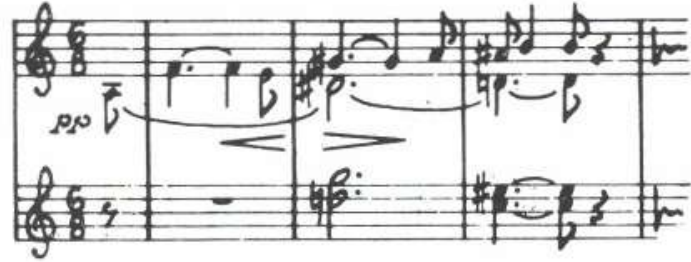

-Toda nuestra cultura europea-dice Nietzche en el prefacio de la Voluntad de poderio- se agita ya desde hace tiempo, con una tensión torturadora bajo una angustia que aumenta de década en década, como si se encaminara a una catástrofe intranquila, violenta, atropellada, semejante a un torrente que quiere llegar cuanto antes a su fin, que ya no reflexiona, que teme reflexionar ${ }^{1}$

En Thomas Mann entonces, y de una manera más o menos continua se mantiene la ambigüedad entre el desarraigo burgués del factor esclavizante y aniquilador $\mathrm{y}, \mathrm{al}$ mismo tiempo, se desarrolla en él la preocupación por los elementos indicadores de la decadencia: la preocupación por la muerte y la enfermedad como centro de construcción espiritual. Existe en él, una tensión permanente entre las posibilidades de autoafirmación conciente derivadas del humanismo clásico, y un pesimismo al cual habia accedido entre otros por medio de Schopenhauery que está referido en su obra a los aspectos más problemáticos de la cultura y existencia humanas, además de mostrar su esencia transformadora y aún aniquiladora; en el Doctor Faustus, como se verá más adelante, se plantea el devenir del arte contemporáneo explicitado por la experiencia musical, de la primera mitad del siglo que termina. Esta manifestación temática adquirirá forma estilistica por medio de la ironia y en su desarrollo ulterior, a través de la parodia.

La tensión interior entre contenidos espirituales históricos diferentes sufrida por Mann (no siempre concientemente) y que lleva a

1 Nietzsche Friedrich. Voluntad de poderio. Madrid:Edaf. 1981.p. 19 tener una actitud distante frente a las democracias políticas del primer cuarto de siglo tiene un ejemplo concreto en sus Meditaciones de un apolitico (especie de manifiesto politico-literario publicado en 1918) donde Thomas Mann se propone ir al rescate de la tradición en contra de la posición gregaria frente a las democracias aliadas actuantes durante la primera guerra mundial:

*Las consideraciones de un apolítico -dice Tohmas Mann en un esbozo autobiográfico escrito en 1930- se publicaron el 1918, en un momento que visto desde fuera era totalmente desfavorable, más aún, imposible: el momento de la derrota y la revolución. Pero en realidad era el momento oportuno. Yo había sufrido y expresado anticipadamente todas las angustias y problemas espirituales que ahora se precipitaron sobre la burguesia alemana, y a más de un lector ésto le sirvió, y no sólo para mantenerse firme; quiero pensar por ello que el libro conserva su sentido y su valor histórico y espiritual sobre todo como una batalla última, suprema, valiente de la burguesia romántica, al emprender su retirada ante lo 'nuevo' ${ }^{2}$

Este fue un libro signado por la experiencia de la guerra, por el odio contra esa incómoda sensación de sentirse en manos extranjeras; fué más bien una experiencia interior y aventurera de Mann más que un planteamiento politico objetivo y coherente. Y es que aunque representó toda su vida un papel de liderazgo espiritual para gran parte de sus contemporáneos alemanes y, en el 'exilio', posteriormente sentó su posición contra Hitler, siempre consideró que en el fondo la gran literatura está muy alejada de las contingencias politicas como lo consigna en algunas partes de sus Diarios, dados a conocer en 1975.

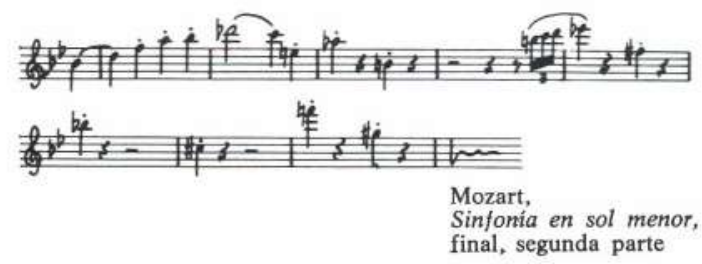


Esta obra, que Mann comenzó a escribir una mañana de mayo de 1943, involucra a muy grandes rasgos, dos personajes centrales: Serenus Zeitblom, profesor de filosofia y representante digno del gran humanismo alemán que está encargado de narrar la vida de su amigo de infancia, el músico Adrian Leverkhün, Fausto del siglo XX, profundamente interesado por la Teologia, que de principio a fin tiene un carácter esencialmente luterano, y que da a su obra y su temperamento un matiz de oscuridad inescrutable.

El abismo espiritual entre el clásico humanista y la naturaleza trágica de su empresa narrativa es un primer rasgo fundamentalmente irónico de la obra. Nuestro genial músico adquiere un tono cada vez más denso en su obra musical, que podria considerarse sin ambages como una milagrosa sintesis de los momentos históricos de la música europea. En su Faustus, Mann introduce un espacio necesario en el cual Leverkhün establece un 'diálogo' con el demonio (que demuestra tener un impresionanate conocimiento del arte, y especificamente de la música). Este diálogo aparece en la novela como un manuscrito de Adrian en manos de Zeitblom. Corresponda o no a una parodia del músico, a un 'hecho real', o a un mecanismo del autor para darle digna autoridad transgresora a la figura de Leverkhün lo cierto es que es un punto que explicita el carácter demoniaco de la empresa, que ya se propone nuestro músico y que expresa una especie de desesperanza del desarrollo del arte (según el sentido clásico) a no ser por la intervención de una especie de dios, que en esta ocasión, es el demonio.

Thomas Mann en su Novela de una novela ${ }^{3}$ nos da cuenta de una particularidad creativa que emplea, y es su capacidad de asociar y re-
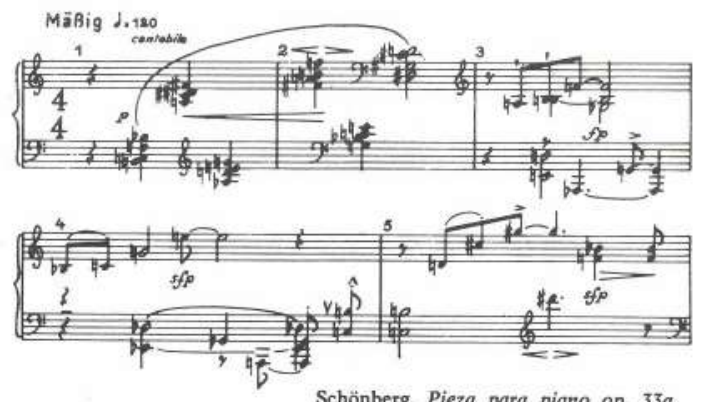

crear circunstancias y personajes reales, para configurarlos en un contexto ficticio y narrativo. De hecho son evidentes, y así lo hace constar en dicho texto, las conexiones entre las ideas musicales de Schöenberg y las que plantea Leverkhün en el capítulo XXII del Faustus. Asi mismo el conocimiento de la tradición musical y su evolución misma corresponden a las del creador del dodecafonismo. Sin embargo debemos estar alertas frente a una cómoda identificación espiritual. Es así como Mann se apropia de los elementos técnicos e innovativos que el genio de Schöenberg crea, apropiación en la cual es asesorado por el filósofo de la escuela de Franckfurt, Teodoro Adorno. Esta irrupción de Mann en el mundo musical de Schöenberg, sin embargo, está dada en un contexto diferente; ahora, la obra que el músico vienés concibe con virtuosismo y sinceridad, se torna en manos de Leverkhün en el fruto herético de sus delirios faústicos.

Al respecto aclara Mann: "...la idea de la técnica dodecafónica, asume en la esfera de mi libro, en ese mundo de pactos con el diablo y de magia negra, un color y un carácter que por su naturaleza, - ¿no es verdad?- aquella no posee, lo cual hace que en realidad, la idea sea propiedad mía, ésto es, del libro" ${ }^{4}$

Es claro entonces, que más que una empatía rigurosamente estética entre Mann y Schőenberg, lo que hay en Mann es una angustia frente a la crisis de occidente, a la enfermedad crónica (expresada también en su magistral obra La Montaña Mágica) de la

\footnotetext{
s MANN. Th. Novela de una novela (o Génesis del Doctor Faustus) Buenos Aires: edición Sur.

4 Ibidem, p. 38.
} 


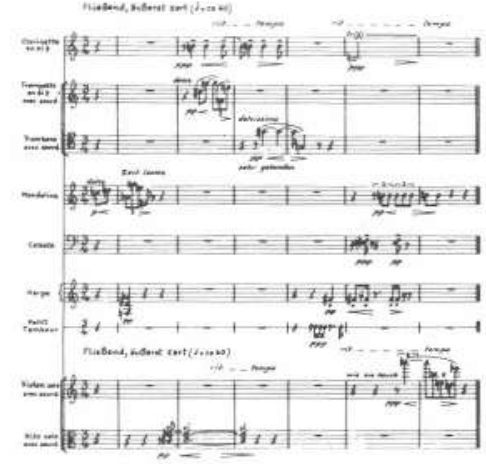

cultura centrada en una razón instrumental y monológica, crisis que se expresa como espiritu de la época en los lenguajes expresionistas (por ejemplo el lenguaje dodecafónico y serial) donde lo feo adquiere categoria dentro de la estética, para mostrar dicha enfermedad.

Otra de aquellas apropiaciones que hizo Mann para construir su monumental novela corresponde a la influencia espiritual, además de anecdótica de Friedrich Nietzsche en el desarrollo del personaje central, de modo que incluso se ha sugerido que la obra es una novela sobre el filósofo alemán. De hecho, muchas de las secuencias del libro ocurridas a Leverkhün son extrapoladas de la vida de Nietzsche: la visita al lupanar de Colonia con la escena del piano, el papel transformador de la enfermedad (sifilis), el matrimonio fallido, etc. son hechos que Mann recrea paródicamente para construir su novela de época, que culmina después de la muerte del artista del mal en un contrapunto histórico con la narración de Zeitblom y la desagarradora capitulación alemana terminada la segunda guerra mundial.

En Doctor Faustus serenidad, mesura y distancia critica se vuelcan sobre el ficticio narrador Serenus Zeitblom. Sin embargo tanta mesura tiene su contraparte trágica y transgresora en el carácter artísticamente malvado de Adrian Leverkhün. Este personaje fue concebido por Thomas Mann, como lo deja entrever en Novela de una novela (génesis del Doctor Faustus), como una suma de espiritus, vivencias y circunstancias ocurridas en verdad a personajes de la historia de la música y las letras. Es en el Doctor Faustus donde Mann explicita muy claramente la tragedia de la modernidad estética clásica, es decir de aquella tendencia cuya esencia es la razón estética autorreguladora.

En Faustus, Thomas Mann toma como base para su análisis de la crisis del arte clásico, el más trascendental y abstracto de todos los fenómenos estéticos: la música. Adrián Leverkhün es el espiritu romántico que ha llegado al punto culminante de la crisis de la modernidad estética musical, iniciada desde el manierismo con Gesualdo, príncipe de Venosa, Claudio Monteverdi, Andrea y Giovanni Gabrielli, y explicitada en términos de ruptura con la tradición casi 400 años después, con la segunda escuela de Viena (Arnold Schöenberg, Anton Webern y Alban Berg).

El adiós a la forma sonata que Mann muestra a través de la interpretación de la sonata para piano op. 111 de Ludwig Van Beethoven, que Leverkhün, personaje central de la novela, escucha en las conferencias de su maestro de música Kretzschmar es el adiós que la música moderna de principios de nuestro siglo le hace a toda la tradición tonaly formalista que habia gobernado la cultura occidental, con sus jerarquias formales y tonales, con su satanización de la disonancia y su predecibilidad.

-Bastaba, nos dijo (Kretzschmar) con haber oído la obra para responder a la pregunta. ¿Un tercer tiempo? ¿Una vuelta a empezar? ¿Después de un adiós como aquel? ¿Un regreso después de aquella separación? ¡Imposible! Habia sucedido que la sonata en aquel segundo tiempo, aquel enorme tiempo, se habia terminado para siempre. Y cuando él decía «la sonatan no se proponía únicamente designar aquélla en do menor, sino la sonata en general, en cuanto género, en cuanto forma tradicional de arie; había sido ahora 
conducido a fin, a tener un fin; había cumplido su destino, alcanzado su objeto insuperable; se abolia y se desataba, se despedia -la señal del adiós del motivo "re, sol sol" suavizado melódicamente por el do sostenidoera un adiós también en este sentido general, un adiós grande como la obra, el adiós de la sonata, 5

Había sucedido que la forma mayor de la tradición clásica era la sonata, normatizada a través de la primera escuela de Viena (Mozart, Haydn y el Beethoven juvenil). Era necesario comenzar con la ruptura de esta forma, y con ella, renunciar a toda nostalgia por el pasado, actitud espiritual muy ligada al romanticismo.

Como se dijo anteriormente, Leverkhün es un excelente conocedor de la historia de la música. Conoce a Palestrina, Monteverdi, Bach, Clementi, Vivaldi, Corelli, Torelli, Mozart, Beethoven, Schubert, Liszt, Schumann, Wagner y Mahler;

"Aquello comenzó con toda naturalidad: el maestro (Kretszchmar) le demostró (a Adrian Leverkhün) el mecanismo de la sonata en Clementi, Mozart y Haydn. Pronto pasó a la sonata para orquesta, la sinfonia, y presentó en la abstracción del piano -a aquel muchacho que estaba siempre vigilante, atento, con las cejas fruncidas y los labios entreabiertoslas diversas modificaciones que habia experimentado bajo la influencia del tiempo, y de la personalidad aquella expresión, la más rica del arte; aquella que por los caminos más diversos se dirige a los sentidos y al espiritu. Tocó para él obras experimentales de Brahms y de Bruckner, de Schubert, de Roberto Schumann, de compositores más recientes y ultramodernos y, en el intervalo, de Chaikovski, Borodin, Rimski-Kórsakov, Anton Dvorak, Berlioz, César Franck y Chabrier." ${ }^{6}$

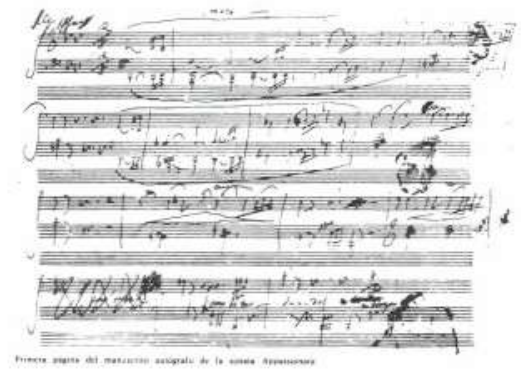

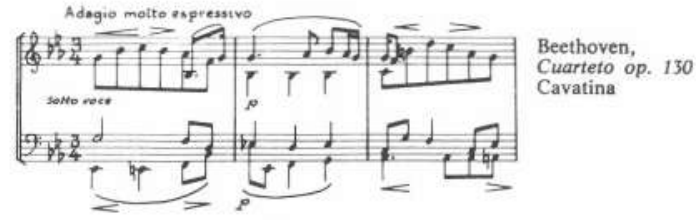

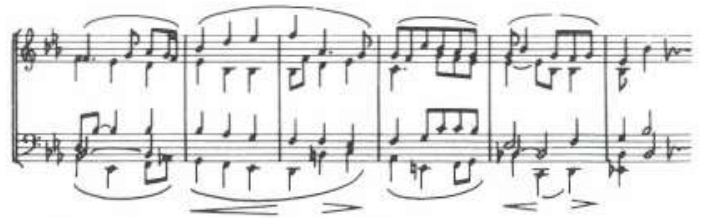

Sabe el origen del problema y quiere proponer un lenguaje nuevo, una estética revolucionaria, que debe, entonces, entrar en contradicción con la estética tradicional. La disonancia, satanizada por la armonía clásica, seria ahora el pilar de la nueva música. La consonancia hacía alusión temática, la cual remitia a una necesidad de desarrollo y conclusión de dicho tema ${ }^{7}$;

La consonancia era sinónimo de predecibilidad, de destino divino, de presencia de un dios que regia los destinos claros y prometedores de la Humanidad que a su vez habia llegado al culmen de su desarrollo: la Ilustración, la mayoria de edad al decir de kant. El cumplimiento de los cánones aúlicos de la subjetividad burguesa en decadencia que Mann coloca como protagonista ya no es posible. Las formas clásicas, excedidas ya por el romanticismo, desde el gran Beethoven, deben superarse. Para ello, es necesario construir otro sistema cuyos elementos sean casi antagónicos a los elementos de la estética clásica. Por esta razón Schöenberg busca trabajar en el mundo de la disonancia, representando así la conciencia de la escisión, la ruptura con una razón centrada en el

5 MANN Th Doctor Faustus. Op. cit. p. 67.

6 MANN Th. Op. Cit. p. 91 y 92

7 Nos referimos a la forma estructural ( $A B A^{\prime}$ ) de la forma sonata, cuyo modelo se impuso en toda la composición musical académicadesde Manheim. Este modelo sigue la lógica del discurso literario: tema (A). desarrollo argumental del tema (B) y sintesis ( $\left.A^{\prime}\right)$, conclusión o reexposición. Es contra esta lógica que la música moderna lucha. La disonancia rompe con toda estructura de análisis dentro de esa lógica clásica, lo cual significa romper con una especie de camisade fuerza, que habia 'detenido' los procesos libertarios del arte de la música en los años anteriores a la revolucióndodecafónica y serial. 


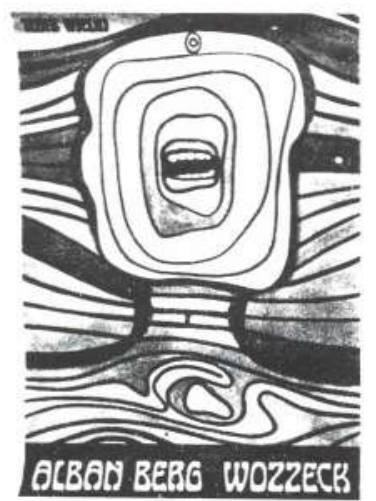

sujeto psicológico, como lo es la razón estética romántica (llamado también el sentimiento romántico), para penetrar en otra racionalidad, donde la objetividad penetra de nuevo en la esencia de la música (como había ocurrido ya en el siglo XVIII) ahora bajo el signo de la matemática, la economia de términos, y la expresión intelectual de una visión escindida y descentrada del mundo, rasgo inherente al arte contemporáneo y que corresponde a su aspecto acultural, ésto es, ese pequeño resquicio que se resiste a prolongar los esquemas socioculturales vigentes.

Si Leverkhün es Schöenberg desde el punto de vista musical, encontramos en Thomas Mann una actitud de ambigüedad frente a la revolución dodecafónica y a la propuesta moderna de Schöenberg, respecto al trabajo con la disonancia y la ruptura, entonces, con todos los modelos clásicos. El hecho de que Leverkhün venda su alma al diablo para poder crear ese nuevo lenguaje, nos muestra la actitud clásica de Mann. Es decir: la identificación entre lo áulico y lo divino con la armonía tradicional por un lado, y por otro, la identificación entre la disonancia y la deformidad con lo demoníaco. Si Leverkhün opta por lo demoníaco, es porque no le queda otra alternativa para expresar la decadencia del arte occidental y de occidente en general.

"¿La obra de arte? (pregunta Leverkhün) una engañifa, una cosa que el burgués querria que todavía existiese. Va contra la verdad y la seriedad. Sólo es auténtico y serio lo muy breve (va contra la grandilocuencia del romanticismo nacionalista). El instante musical concentrado en extremo ... (...) la aparien- cia y el juego, tropiezan con la conciencia del arte. El arte quiere cesar de ser una apariencia y un juego; quiere convertirse en un conocimiento lúcido (es decir en un nueva racionalidad) $\% 8$

Es decir, el arte moderno con su estética de lo feo, su ruptura de las formas, su propuesta dodecafónica, su sentido de la fugacidad planteado desde el naturalismo impresionista, expresa lo que Hegel llamó el espíritu de la época. Las siguientes son palabras de Adrian antes de caer definitivamente en la incomunicación y la locura:

-Pero harto comprendia que estamos en tiempos en que se ha hecho imposible realizar una obra por vias virtuosas regulares, $y$ sirviéndonos de medios lícitos. El arte se ha vuelto ya impracticable sin la ayuda de Satán y del fuego infernal, bajo la caldera...Sí, sí, queridos compañeros, el arte se halla en un punto muerto, y por haberse vuelto demasiado grosero, se burla de si mismo, y la pobre creatura de Dios ya no sabe a qué santo encomendarse en medio de su angustia, y sin duda ésto es culpa de la épocan, ${ }^{9}$

La excelente novela Doctor Faustus es, sin lugar a dudas una obra que tiene varios niveles de lectura: desde lo anecdótico hasta lo filosófico, pasando por lo histórico, lo politico, lo ético, lo estético, lo musical propiamente dicho, los sentimientos más desgarradores y profundos del ser humano o las pasiones e ideales más sublimes. Doctor Faustus puede ser considerada como la más ambiciosa obra de Mann, si la asumimos bajo uno de esos planteamientos temáticos: el destino del arte y el artista en la contemporaneidad, tanto asi, que la inefable empresa narrativa emprendida tiene que convertirse, como lo manifiesta el crítico Erich Heller, en su propia crítica.

El siglo ya vive su ocaso, y la obra del "mago* de Lübeck sobrevive al reto alli planteado, al terror frente a la esterilidad y al reconocimiento de lo demoniaco, regulado aqui por un humanismo clásico, en el campo de la apertura ética y estética. 